\title{
Challenges, Opportunities, and Potential Roles of the Private Primary Care in Tuberculosis and Diabetes Mellitus (TB-DM) Collaborative Care and Control: A Qualitative Study
}

\author{
Merita Arini ( $D$ merita.arini@umy.ac.id) \\ Universitas Muhammadiyah Yogyakarta \\ Dianita Sugiyo \\ Universitas Muhammadiyah Yogyakarta \\ Iman Permana \\ Universitas Muhammadiyah Yogyakarta
}

\section{Research Article}

Keywords: chronic disease, public-private mix, private primary care, multimorbidity

Posted Date: February 8th, 2021

DOI: https://doi.org/10.21203/rs.3.rs-153508/v1

License: (c) (1) This work is licensed under a Creative Commons Attribution 4.0 International License.

Read Full License 


\section{Abstract}

Introduction: TB-DM is a new looming global co-epidemic problem. Despite the Indonesian Government's ongoing effort to put the collaborative TB-DM management regulation in place, it has not taken into account the involvement of private primary care (PPC). This study intended to capture the PPC's existing practices and explore their challenges, opportunities, and potential roles in the collaborative TB-DM services and control.

Methods: A descriptive qualitative research design was used to collect data. Two Focus Groups Discussion (FGDs) were conducted with 13 healthcare workers (HCWs) from different private clinics and nine private general practitioners (GPs) from Yogyakarta City, Indonesia. We triangulated the data with the FGDs of HCWs community health centers (CHCs) and in-depth interviews with three regional health regulators. The discussions were audiotaped, transcribed verbatim, and subjected to thematic analysis.

Results: PPCs have not been initiated to be involved in the implementation of collaborative TB-DM program. The themes obtained in this study were health system-related barriers, HCWs' knowledge and perception, un-implemented bi-directional screening, and multisector role needs. The PPCs' potential roles identified are to conduct health promotion, bi-directional screening, patient referring, and data reporting according to the TB-DM program indicators.

Conclusion: Although its involvement in implementing collaborative TB-DM services has yet to be taken into account, the PPC's potential role should not be neglected. Therefore, it is essential to increase their involvement by enhancing their capacity and improving the Public-Private Mix. PPC engagement should be initiated and maintained to ensure the sustainability of the program.

\section{Introduction}

In recent years, Tuberculosis (TB) and Diabetes Mellitus (DM) are two of the ten leading causes of death in the world [1]. There has been increasing comorbidity of both diseases as the new looming global coepidemic [2]. This condition represents complicated growing problems, which are including communicable and non-communicable diseases in a problematic context. As a significant TB risk factor, DM prevalence among TB patients ranged between $1.9 \%$ and $45 \%$ and continuously increased $[3,4]$. Meanwhile, TB prevalence among DM patients varied from $0.38 \%$ to $14 \%$ [4]. Hence, the TB-DM collaboration program was then declared one of the WHO's TB eradication strategies since 2011 and included an essential aspect in efforts to achieve Sustainable Development Goals (SDGs) $[5,6]$.

Indonesia still has the second-highest number of TB cases in the world [3]. Despite the increase in TB reports, there is still a significant difference between the reported number of incident cases (7.0 million) and the estimated 10.0 million new cases in 2018. This discrepancy is attributable to the co-existence of underreporting and low diagnosis of case identification. Indonesia is responsible for $10 \%$ of this gap in the world [3]. This situation is exacerbated by the evidence that TB is closely correlated with DM in Indonesia [7]. As well as being known that DM worsens TB outcomes and leads to TB treatment failure, 
DM often causes TB patients to be unrecognized due to non-typical symptoms [8]. This difficulty inhibits case finding since it often causes diagnosis delays in Indonesia [9].

Turning now to the rising incidence of DM, it adds to Indonesia's double burden of diseases. Indonesia is ranked $7^{\text {th }}$ highest among adults with diabetes in the world [10]. Based on the same report, the prevalence of DM in Indonesia is also estimated to continue to grow each year. TB-DM incidence might become more prone if preventive measures and control efforts are not implemented.

In the context of the current health care structure, Indonesia is supported by vast proportions of the private sector [11]. Most of the initial care seeking of Indonesian TB patients occurred in the private primary care sectors (PPCs), which were limited in diagnostic tools, TB treatment supplies, and inadequacy of health workers' (HCWs') capacity and compliance $[12,13,14]$. Moreover, case notification and TB quality care tend to lag in PPCs $[12,13,14,15]$. On the other hand, DM has become one of the prioritized for non-communicable diseases care since PROLANIS (chronic disease services program) was launched by BPJS-Kesehatan (Indonesia national health insurance). PPCs also ha conducted PROLANIS for a portion of DM patients, while other DM patients are managed conventionally [11].

Given the large number of patients seeking treatment at PPC and its services, specific approaches are needed to increase mutual detection, prevention, and management between TB and DM. Indonesia Government initially established many regulations and programs to boost the private sector's role in TB management through a Public-Private Mix (PPM) [16, 12]. PPM was crucial since extensive evidence indicates that failure to involve private providers used by TB suspects and patients hinders case detection, causing diagnosis delays, contributes to inadequate and ineffective treatment, increases drug resistance, and puts an unnecessary financial burden on the patients [17]. However, these efforts have not yet begun to be applied to the TB-DM collaboration. Therefore, this study's objectives were to assess existing practices, explore challenges, opportunities, and potential roles that PPC can play in TB-DM control and care collaboration.

\section{Methods}

\section{Study Setting}

This study was conducted between June and August 2019 in Yogyakarta City, an urban area with the highest population density district in the central of Yogyakarta Special Region Province, Indonesia. With an area covering 35.2 square kilometers, the population comprises 412,726 inhabitants in 2018 [18]. Medical services of this area are provided through a network of 18 Puskesmas/ community health centers (CHCs), 20 hospitals, 127 clinics, and hundreds of registered general practitioners (GPs) who work in private practices [18].

\section{Participants}


Purposive sampling by criterion sampling technique was applied to select informants. Discussion between two groups of FGDs was conducted with 13 healthcare workers (HCWs) from different private clinics and nine private GPs. Representative health providers from private clinics and independent GPs were invited from the list of health facilities registered in the Yogyakarta City Health Office. They were selected with the inclusion criteria: providing general health services/ non-specialistic care, serving a dense patient population, and/or cooperating with national health insurance (BPJS-Kesehatan).

\section{Study Design and Data Collection}

This study was a descriptive qualitative study focused on private providers' perspectives and experiences in TB-DM care and control. As a part of umbrella research in both diseases management in Yogyakarta City, this study's primary unit analysis consisted of private providers in two separate FGDs: private GPs and clinics. We also triangulated the data collected above to the following six groups FGDs with 24 health workers from 18 Community Health Centers (CHCs) and three DHO in-depth Interviews (IDIs) at the next stage of this research.

The FGDs and IDIs were guided with open-ended questions and discussion guidelines. The guideline consisted of questions to explore knowledge and awareness about TB-DM, existing TB-DM care and control strategies, problems and barriers impacting the delivery services in private health care, and opportunities to make comprehensive services for both diseases. The FGD guidelines were pilot tested on subjects with similar characteristics as the research informants prior to use.

Each FGD and interview took approximately 180 and 30-60 minutes, respectively. FGDs and IDIs used a combination of Indonesian and some local Javanese languages. FGDs were held in meeting rooms of the $\mathrm{DHO}$ area. Meanwhile, IDIs were conducted in some quiet rooms of DHO, as chosen by the informants. The FGDs and IDIs were conducted separately at different times. All FGDs and IDIs were recorded on audio. The IDIs and FGDs continued until saturation was reached, which indicated that no new theme emerged.

Data credibility was ensured during the FGDs and interviews process with multiple approaches. As described above, we conducted investigator triangulation, data source triangulation, and asking questions repeatedly in a rephrased way to confirm the informants' answers [19]. All of the authors were involved in data collection. FGDs of HCWs were conducted by DS and IP as moderator, while MA became an observer. The first author (MA) also performed IDIs with DHO officers. All three authors have a background in qualitative research training and practices. Both MA and DS are female. MA is a medical doctor with a hospital administration background, while DS has expertise in public health and nursing. The other, IP, is a male medical doctor and a researcher in the chronic care area. As for sources triangulation, we triangulated the data with the FGD of CHCs health workers and in-depth interviews with three regional health regulators.

\section{Data Analysis}


The research assistant did careful verbatim transcriptions from FGDs and IDIs audio tape-recorded. She has a health background and was also trained in qualitative data collection. Transcripts were not given to the informants but were rechecked by MA and the research assistant before coding. Thematic analysis was applied using nVivo 12.0 to manage the coding, categories, and generating the themes. Read and reread transcripts of IDIs and FGDs also conducted to search new trends and recurrent concepts. Codes were allocated to segments of the text, and similar codes were then assembled to form a category. Similar categories then collaborated as a theme. Furthermore, all authors reviewed and discussed the results of the data analysis.

\section{Results}

The study participants described current practices in the provision of TB-DM services, identified complex challenges affecting the integration of both disease care. They explored the opportunities and potential roles of PPC. The main four themes identified from the data analysis were health system-related barriers, HCW's knowledge and perception, un-implemented bi-directional screening, and multisector role needs.

\section{Theme 1: Health System-Related Barriers}

In our study, private GPs/ solo providers more frequently found TB-DM cases among their patients than clinic staff who have never had the cases at all until now. Although all TB-DM cases were always referred to a hospital and/ or Puskesmas, some private-sector challenges related to TB-DM services were identified as health system-related barriers. These problems occurred due to the in-adequate collaborative system from national into the local network.

In this first theme, five categories were identified. These categories include BPJS-Kesehatan procedure, health financing, diagnostic procedures, health facilities networking, and human resources issues.

\section{BPJS-Kesehatan procedure}

As a national social security agency for health, BPJS-Kesehatan has some mismatched regulations with TB-DM services provision needs. Almost all informants in this study remarked that regulation restrictions for non-specialist referrals made it challenging to do hospital referrals. According to this regulation, TB is a disease that must be managed by primary care facilities. The problem occurs mainly if DM patients had atypical TB symptoms and required a chest X-ray for TB screening. As well-known, almost all primary healthcare facilities in Indonesia have no radio imaging equipment for these purposes.

"The problem will arise if the patient DM needs to screen TB. Not all of them have symptoms because there is an immune response, while the national consensus suggests using $X$-rays to check effusion or infiltrates. Meanwhile, the primary health facility did not have X-rays facilities, but referral (to the hospital) could not be done due to this BPJS regulation." (FGD Clinics, $R 7$ )

The complexity of electronic referral and re-referral forms that must fill out by doctors was also not acceptable. Some senior doctors often face barriers due to non-user-friendly applications or may be due 
to illiteracy of new technology, i.e., in completing the TACC (Time-Age-Complication-Comorbidity) section for referring patients to a hospital. Complicated procedures of patient referral sometimes lead to fraud in diagnosis writing, as disclosed by informants.

"There was a case yesterday. A patient was diagnosed with DM in my clinic, then he complained of prolonged cough, and so on. Then I referred him to the hospital with the same diagnosis that other doctors had reported earlier (Bronchitis). Since we were not able to refer (to the hospital) with a diagnosis of $T B$, so we wrote Bronchitis."(FGD Private GPS, R6)

\section{Health financing}

Interesting issues pointed out by private sectors was related to health cost beyond the national health insurance scheme. Since the TB program was established in Indonesia, services are mostly provided at CHCs. Private clinics/ GPs are allowed to refer TB patients to these public health facilities. Due to some patient participation in BPJS are not registered at the $\mathrm{CHC}$, specific procedures and services require additional fees, i.e., registration/ administration, cost-sharing, and/or payment of fees for supporting examination or other health services needed. Health costs barriers arise not only because of the patient's inability to pay but also because of a low willingness to pay. In turn, this barrier will disrupt patients from accessing health services according to their current needs.

"The patient often say, 'How will it cost, Doc? If I am told to pay, I am (still a BPJS membership) here ....' So far, BPJS patients only know if BPJS participants should not pay anything. Anyway, they all know (that health services) should be completely free." (FGD Private GPS, R4)

"Patients do not pay (for TB services at the Puskesmas), but every month a patient visits, they must register. Every time a patient registers, they have to pay, so instead of being complicated, it is advisable to move their BPJS membership to Puskesmas."(FGD Private GPS, R3)

On the other hand, there are several types of PPCs located in Yogyakarta City. Variations of the PPCs' ownership, organization/ managerial, and membership coverage have existed even before the universal health coverage $(\mathrm{UHC})$ era. This situation has left a variety of health programs and potential sources of health funding in addition to the BPJS-Kesehatan scheme that could be used in TB-DM care and control.

"There are funds allocated to National Police officers for annual health checks, but this is not routine, either. It needs to be separated and sorted, and it takes turns for the individuals being examined."(FGD Clinics, R11)

"Because the company also covers our health costs, so even without BPJS, a patient can seek treatment outside. Yes, we discuss it there (with the patient)."(FGD Clinics, R9)

Diagnostic procedures 
The informants expressed that chest X-ray screening, which is suggested by national guideline, have been procedurally constrained, as explained above. In general, private health workers are not familiar with the other tests, such as gen-Xpert/ rapid molecular test, even though DHO promoted gen-Xpert for increasing TB case finding in Yogyakarta. Instead of being more accessible, the diagnosis by sputum smear test was very challenging in DM patients. Informants conveyed that they always refer the patient to a third party if they require a supporting exam to validate a TB diagnosis. These conditions were challenging for proper and timely diagnosis in suspected patients.

"We are also in the same situation as other clinics that do not do supporting examinations by ourselves. But, we cooperate with third parties, including sputum examinations and X-rays." (FGD Clinics, R9)

Health facilities networking

The informants highlighted the weakness of networking between health facilities. Even though private health facilities cooperate in immunization, diarrhea, and other national programs, TB collaboration control, and care are un-established. The majority of private HCWs informants were not familiar with the concept of Public Private-Mix (PPM), nor do they have a cooperation MoU with the local Puskesmas, mainly in TB management. However, discussions to initiate MoU formulation have been done since accreditation for all primary health facilities were implemented.

Data recording and reporting are the other essential components that should be discussed in the development of MoU between PPC and Puskesmas. However, most informants expressed mixed feelings between their desire for MoU to increase authority in health services and potential obstacles that would be faced. The solemn reporting obligations, how to report, and un-established reporting system were complex challenges that need to be resolved.

"I do not know my obligation to report to the Puskesmas. This challenge is about how to establish cooperation with the Puskesmas. We are asked to propose MoU cooperation (to Puskesmas) as required by BPJS and for the TB disease eradication. Private GPs also has to play a role, it must be a written MoU cooperation, and so far, I have tried to propose it, but the Puskesmas has not answered yet. The word formulation of MoU is still being discussed with the Health Office; what kind of cooperation is this. The formulation cooperation is still in the process." (FGD Private GPs, R5)

Another reported problem was communication and coordination between private and public primary care and hospitals. Although some of the GPs informed that they have an excellent relationship with public health workers, in general, but they still experienced minimal feedback or responses from referral healthcare facilities. Some of the referrals never received feedback, and they were lost during the followup for the patient.

"There is a TB patient who is a BPJS participant also, and we just handled once. And maybe we don't know the procedure, because we just got it. If I am not mistaken for the treatment, this is served in the Puskesmas around the patient's house; that is the closest Puskesmas. Yesterday, because of the 
information from the Puskesmas close to our clinic, the last case had to be reported. So, there was a miscommunication. That is our problem when there is no communication between the Puskesmas and our clinic. (FGD Clinics, R2)

The District Health Office (DHO) and CHCs acknowledge that the private sector has not been involved in TB-DM care and control collaboration. From the perspectives of DHO officers, private sectors seemed to lack attention to government programs. On the other side, the DHO is preoccupied with many of the Government's health program burdens, including the Minimum Service Standards' target achievement. Hence, the DHO is still more focused on fostering Puskesmas as a Regional Technical Implementing Unit than private sectors.

"To be honest, because of the progress, yeah... TB-DM has not yet reached them (PPC). Because on the way, even on applying DOTS, their attention is low. So, we prioritize what we can do.(IDI DHO officer, R1)

\section{Human resources issues}

Although private HCWs showed positive attitudes by stating the possibility of assisting and being involved in TB-DM management, they still pointed out human resources issues that lack designated staff in TB programs. TB and TB-DM patients need to be adequately managed according to DOTS (Directly Observed Treatment Short-course) strategies. There was still limited PPCs' staff who were trained for DOTS/ TB management programmatically. Meanwhile, a portion of chronic non-communicable disease patients was managed systematically with PROLANIS (BPJS chronic disease service program), although it still needs improvement.

"Our problem is that there is no person in charge (PIC) for TB cases. For DM and Hypertension, whose patients are members of PROLANIS, there is a designated appointed PIC. There is no PIC for TB at us, but we have a quality and patient service department that will further explore TB cases even though we rarely have cases. DM and Hypertension patient always managed and followed-up, but because TB patients go directly to the hospital, we don't have TB PIC." (FGD Clinics, R2)

\section{Theme 2: HCWs'Knowledge and Perceptions}

Informants expressed wide variations in the baseline of knowledge and perspectives on TB-DM and its management. Three categories were emerged, i.e., variation knowledge in TB-DM, false perceptions, and lack of TB socialization and training.

\section{Variation of HCW's Knowledge about TB-DM}

During the discussion process, private HCWs showed diversity in their knowledge of the pathophysiology of TB-DM, treatment, type of screening, and standard treatment. Although most informants realized that DM was a risk factor for TB, none of them mentioned if TB patients also have a risk factor for DM. Informants, who expressed their opinions, generally understood well the impact of DM on worsening TB patient outcomes. 
"Based on the theory, handling TB with DM or DM with TB will be more difficult." (FGD Clinics, R10)

"If I was asked about the relationship between DM and TB, in my opinion, it is related. Because it is associated with the immune system, which might at that time if we conduct anamnesis, it is indeed experiencing a decline in these patients."(FGD Clinics, R9)

\section{False Perceptions}

Some clinics' health workers perceived that TB-DM was rare because they had not or only seldom found the case. In the diagnostic procedures and treatment aspect, almost all private HCWs also still have a preoccupation that procedurally TB-DM is difficult to manage even though various government policies allow this to be done. They believe that the patients cannot get insulin if their $\mathrm{HbA} 1 \mathrm{c}$ level was lower than $9 \%$, according to the BPJS-Kesehatan requirement, even though this requirement not applicable for patients with comorbid conditions.

"As long as I practice in the clinic, I have not found DM patients with TB symptoms. We haven't. I've never got a TB-DM case while practicing there. So, I haven't thought much about how the relationship between the two diseases."(FGD Clinics, R2)

"This is another problem. Insulin can only be given if HBA1c above 9. Yeah, that is just a new problem, recently."(FGD Private GPs, R5)

Lack of TB socialization and training

Variation of knowledge and perceptions among HCWs may occur due to a lack of training, socialization, and coordination between them, public sectors, and DHO. Only one private GP reported being invited to TB training in 2015. All private providers stated that they have never seen or read the guideline or national consensus about TB-DM. This situation also causes HCWs to be unaware of the importance of bidirectional screening, regimen standard, and integrative care for TB/ TB-DM patients.

"The Health Office is already undertaking a lot of accreditation-related socialization intensively. But, in my opinion, socialization regarding new guidelines and regulations (about TB-DM) is still limited."(FGD Clinics, R2)

\section{Theme 3: Un-implemented bi-directional screening}

In this vital theme, three categories were identified. These categories include screening pathways, screening difficulties, and screen opportunities.

Screening pathway

None of the private HCWs stated that the bi-directional screening was being done comprehensively and regularly in their health facilities. TB screening in DM patients was performed sporadically, which was 
only superficially investigating if patient complaints. This screening was usually performed based on the physician's clinical judgment or if symptoms suggest a suspected TB disease appear.

"... the problem is (only) if there are complaints, we then anticipate it. Complaints of cough are rarely or not become the patient's main reason to come for treatment. There could be inaccuracy or inadequacy during the history taking due to many patients, long queues, and many more. So, we only explored the primary diagnosis (DM) or if the patient did not appear to be coughing in the room. It was considered sufficient to ask cough complaints, especially in DM patients who generally only checked the blood glucose then asked for the referral form and finished. It's not well organized."(FGD Clinics, R6)

Screening difficulties

Informants noted that some factors could become obstacles in bi-directional screening implementation. It was highlighted that DM patients often have atypical symptoms or could not expectorate or produce sputum for smear examination. The difficulty of accessing $X$-rays also remains a prominent obstacle in implementing bi-directional screening. On the other hand, patients who refused to be referred for diagnostic procedures might also delay the diagnostic examination.

"It's not easy to diagnose TB, either, because there are many elderly patients who say that, 'When I'm old, it's common that I have a prolonged cough.' There are still a lot of opinions like that. 'It's a cough because I'm an old man.' So he came back two months or three months later. The cough does not heal, or the child is sick, the family members are sick, the grandchild is sick. It turned out that his grandparent was ill first." (FGD Clinics, R3)

"The X-ray might facilitate the technique, whereas the sputum screening test is difficult."(FGD Private GPS, R3)

\section{Screening Opportunities}

Despite complicated existing obstacles, the informants identified several opportunities to screen for TB in DM patients. Some routine activities that have been done routinely before can be used to start TB screening intensively, i.e., initial assessments by HCWs in health facilities, general routine check-up examination, and Posbindu/ Posyandu (integrated community health services post).

"We also carry out routine activities for the National Police, which are periodic for Polri (Police of Republic Indonesia) members themselves as well as X-rays and so on. So that it is found that members of the police who should be healthy, who so far have no complaints, we direct them to the clinic or the hospital." (FGD Clinics, R11)

Some informants also reported that 'fee for service' or non-BPJS patients were more flexible for screening procedure uptake. Some patients usually would pay for diagnostic procedures suggested by the doctor. 
"Our advice to patients, for example, 'If you haven't had an X-ray for the last three months, I recommend Xrays.' If he is not a BPJS patient, it will be more comfortable, but for this BPJS patient, it's still a bit difficult to do."(FGD Clinics, R7)

\section{Theme 4: The needs of multisector roles}

TB-DM patients need to be managed collaboratively. Hence, the functions of stakeholders, health facilities, and also health organizations/associations have a crucial part to play. Many DM patients sought health care in private health facilities. Meanwhile, to involve and engage private sectors, the needs for multisector supports were identified.

Five categories organized this theme. The categories were roles of DHO, roles of health facilities/ health profession associations, patients' roles, potential roles of PPCs, and encouragement by BPJS-Kesehatan.

Roles of District Health Office (DHO)

DHO has keys roles in initiating the private sector to involve in TB-DM collaboration. Socialization for private primary care has not started yet; hence DHO should ensure that all health facilities which serve TB/DM are well informed about this new program. Such a strategy could use the DHO, i.e., by engaging healthcare/profession associations.

"If I may suggest how if the Health Office cooperates with professional organizations in socialization regarding new guidelines, new regulation, or the program of the DHO itself in the city. Because Asklin (private clinics associations) already accommodates almost all private clinics in their respective cities. So, in my opinion, if the $D H O$ reaches them, it will be much easier than the $D H O$ approaches private primary care one by one. (FGD Clinics, R2)

In addition to socialization and beginning to connect or coordinate with relevant organizations, systematic monitoring in health facilities should be considered to ensure the program implementation. The private sector needs guidance, monitoring, and evaluation for program implementation. They also need advocacy about an appropriate payment mechanism.

"We have come to attend DHO socialization on other topics, but usually just socialization. We do not get any guidance or monitoring and so on to ensure its implementation." (FGD Private GPs, R9)

"We have not done that screening. Because clinics are also not burdened for screening, right? Well, who pays the fee? So, if there are clinical symptoms and support the suspicion of the disease, we refer (to hospital/ Puskesmas)." (FGD Clinics, R2)

Roles of health facilities or health professional associations

Asosiasi Klinik (Asklin), or private clinic association, which accommodates all private clinics in Yogyakarta City, has not been involved in initiating the collaborative TB-DM program in private health facilities. This organization also focuses more on its function in advocacy or assistance for members on 
accreditation and issues related to BPJS-Kesehatan rather than support from other government programs.

"Asklin, until now, the focus is still on accreditation related to the BPJS requirements that in 2021 all health facilities must be accredited. .... As far as I know, Asklin, the focus is still more on accreditation. As for seminars or programs, there is not yet a particular program for it (TB-DM)." (FGD Clinics, R6)

Asklin could play some roles in increasing private sector engagement with government programs. Until now, only limited programs have had a reasonably good collaboration between the public and private sectors, such as immunization and DHF (Dengue Hemorrhagic Fever). Although TB has been initiated in various public-private mix activities, its implementation has not yet been going well. Hence, Asklin can play a role in designing the MoU of cooperation between PPC and government health facilities and conducting various educational sessions or socializing national programs to its members.

"Asklin's role was included due to the BPJS credentialing this year requiring an MOU with the Puskesmas so that Asklin then intervened in the clinic's relationship with the Puskesmas (CHC) because before that it was only independent between the clinic and the Puskesmas concerned."(FGD Clinics, R2)

Roles of health profession associations similar to Asklin could be an extension of the health office to disseminate information about priority programs. IDI/ Ikatan Dokter Indonesia (GPs Indonesia Association), specialist doctor associations, and other organizations of HCWs have not been much involved until now. Although in the discussions of the several national-level consensuses, health professional organizations have often been invited to discuss.

"... In my opinion, it is much easier than the DHO call or comes to each private primary health facilities. Because it does not represent all primary care, maybe if the health office calls the health facilities, DHO will invite large health facilities or from a certain area only. But if DHO can hold Asklin or professional organizations, all of them have been accommodated. It is more coordinated." (FGD Clinics, R2)

Patients' roles

Patients also have essential roles in the successful TB-DM collaboration of care and control. Patients' key roles involve compliance with treatment and following doctor advice, involvement in decision-making, and willingness to pay some health costs and other financial burdens related to diagnostic and treatment beyond the insurance scheme.

"Yes, we first check with X-Ray. In our clinic, when there are X-ray and sputum data that leads to TB, we will discuss it with the patient. I have previously conveyed and because of the absence of drugs and so on. We will discuss whether he is willing to be referred (to other health facilities) because the BPJS is not used here. Generally, that is the case." (FGD Clinics, R9)

Potential roles of private sectors

Page $12 / 22$ 
Informants mentioned some activities that are routinely conducted by PPCs. Some activities listed as potential roles that they can apply if involved in TB-DM control and care collaboration. Private health facilities commonly have a large number of DM patients. Hence, health promotion and patient education become a significant factor for prevention, increasing patient compliance to treatment, and patient referral. The BPJS membership versatility and partnership characteristics between patients and providers in PPCs are also opportunities for program success. In general, patients have a close relationship with health workers, and PPC is highly accessible also. National insurance membership is also quite flexible, which means that participants can temporarily move their health facility membership during TB treatment to Puskesmas or other DOTS facilities if they are worried about additional health service costs.

"We are closer to the patient so that they are more able to warn against routine treatment because usually... those with chronic comorbid diseases routinely come every month. We can order them that even if they take medicine at the hospital with a control letter, "If anything happened, please come to our practice!' If they want a consultation, please come, and they are happy. They sometimes meet a specialist doctor in the hospital, but he doesn't even hold them because there are so many patients. And by that way, we can monitor them." (FGD private GPs, R4)

Referring patients to DOTS facilities is the only effort that can now be done by PPCs when identifying suspected TB-DM patients. This situation was caused by several issues related to PPCs' authority, including untrained staff, unavailability of TB drug regimens according to the current ISTC's standards, and the inability to prescribe insulin. When patients are finally referred to other health facilities, PPC often has difficulty in following up the patient's treatment because of minimal feedback and coordination, as stated above. Thus, challenges on continuity of care have also emerged as obstacles.

"We were unable to order TB drugs. The TB patients who came to us were detected coughing through anamnesis. Then, even for sputum smear examination, we are also referring to a third party. After he is positive for TB, we will return him or educate him to take medication at the Puskesmas in the local area where the patient lives. However, in monitoring TB patients, we are not very involved there." (FGD Clinics, R2)

Although some barriers are mentioned above, private providers expressed their mixed feelings about their ability to be involved in successful TB-DM collaboration. Due to customer satisfaction oriented, they intend always to pay attention to every clinical complaint with appropriate follow-up. However, they also exhibited their reluctance to conduct home visits due to the high workload, even though they are usually required in TB management.

"... if I am asked whether this program can run actively in private health facilities or not, I can say that it can indeed run actively. Because we, from the private sector, always try not to ignore patient complaints. It will be followed up unless there are no complaints." (FGD Clinics, R6)

"Even if we are asked for assistance to make a report as long as we can do it, I think the private sector can be quite helpful, as long as we are not asked to visit the patient's house. It will be a hassle. No 
problem... because I think the private sector will not mind if the Puskesmas can more actively involve us." (FGD Clinics, R2)

\section{Encouragement by BPJS-Kesehatan}

Since BPJS-Kesehatan's role as a significant payor in the national health system, it has encouraged several national programs to run well. Comprehensive care through PROLANIS (chronic care program for DM and hypertension) is one of the commitment-based PPCs' performance assessment items. Informants pointed out their expectations regarding BPJS-Kesehatan's potential role in encouraging screening TB regularly in DM patients.

"BPJS should have regulations to ensure that there must be TB screening in DM cases, for example, in the PROLANIS program. Every six months, there is always an HbA1C examination, complete lipid profile, and urea creatinine. Thus, TB screening could be included in this 6-month program, for example." (FGD Clinics, R7)

\section{Discussion}

This study is the first research to explore the existing practices and readiness of TB-DM implementation in Indonesia from private providers' perspective. In general, our study showed that PPC has many limitations that prevent their active roles in TB-DM control and care. This research's main finding is that the private sector has not started to be involved in TB-DM control and care collaboration. However, unestablished collaborative systems are the main barrier to program integration [20,21].

As indicated in the literature, TB control's effectiveness in achieving desired global targets is contingent upon the effective network of quality and comprehensive health services [17, 22]. Hence, stakeholder agreements and attempts to increase their ownership are necessary to support collaboration [20,37]. Differentiated strategies by region also might be needed to respond to the variation in patients' careseeking trends and enhancing private and public providers' capacity [14, 21]. DHO's roles in regional health management become crucial in established collaborative relationships between these various sectors. Our present study also indicates that TB-DM partnership could be more robust by PPM scaling up and increasing assistance and supervision [21,23,24]. Thus, raising health workers' awareness and improving their quality of care is essential rather than just getting them to socialize [24].

Several studies explained that PPM projects' less promising outcomes had shown insufficient funding and weak governance [21]. It is important to note that the impacts of BPJS-Kesehatan/ national health insurance regulation on care pathways are a crucial aspect to be considered. Although the National TB Program (NTP) covers microscopic examination and TB drug regimen funding, a particular condition of atypical TB symptoms in DM patients needs other procedures, such as thorax X-ray [16, 25]. Our study shows that TB-DM patients also often required some health facilities and professionals' collaborative roles. However, some health services were not accessible due to some health financing restrictions policies. In its implementation, technically, there were also often differences in BPJS-Kesehatan verifiers' 
and HCWs' perceptions that challenging to meet the patients' needs for quality of care. Hence, the formulation of a national collaboration system that should involve major payor agencies and private health service providers is strongly suggested $[26,16]$. Accordingly, our study results indicate the need for further involvement of BPJS-Kesehatan in spur collaboration implementation.

Another important finding was that patients have vital roles in TB-DM care and control success. Consistent with the literature, this research revealed the need to improve patient capacity as the prerequisite of their involvement to gain their compliance in health care services [32, 33]. Hence, selfmanagement support and patient-centered care (PCC) might support successful TB-DM care services as it becomes the critical components in the multimorbid disease care frameworks [9, 34, 35]. On the other hand, patients' burden and cost to access health services also contribute to their timely diagnosis and subsequent treatment appropriately [9]. Thus, patients' complex bio-psycho-socio-economic problems should be solved to strengthen the medical treatment approach $[22,36]$. This finding has important implications for the need to develop a strong connection between private sectors, across government sectors, and community support, i.e., community health workers, NGOs, etc. [17].

This present study shows that TB-DM collaboration's operational constraints were more dominant in TB case finding and management. A possible explanation of these problems is the existence of various interacting factors such as the complexity of the patient's condition, the lack of capacity of PPCs' HCWs in TB management, the unestablished TB program at PPCs, and the complexity of service procedures. The revealed barriers of TB screening in PPCs were in line with the relevant research in several countries. In Pakistan, the existing obstacles of bi-directional screening include difficulties of TB diagnostic in DM patients with atypical TB symptoms, their inability to expectorate sputum, the chest X-ray price, and the distance to the referral health facilities for diagnostic evaluation [27]. In India, TB-DM screening implementation challenges include additional payment, additional visits for diagnostic purposes, poor feedback from referral health facilities, the burden of HCWs, and the need for additional records and reporting [20].

There was a crucial finding that private providers' perceptions about the low number of TB cases identified in DM patients in PPCs might make them doubt bi-directional screening effectiveness. Instead, debates have been presented on how to conduct efficient and effective bi-directional screening [24]. Considering that health workers are the most important stakeholders for the effective delivery of integrated health services, various efforts are needed to avoid their resistance [28].

These study results were also in accord with recent studies indicating that human resources prepared to manage TB issues have not been adequately supported in the private health sector $[12,14,23]$. Insufficient capacity due to untrained private providers in TB management is a common problem in many countries that initiate TB-DM collaboration. Lack of training in TB screening procedures exists in India [20]. Meanwhile, in Ethiopia, HCWs indicated a lack of knowledge and skill in DM management [28]. Nigeria also reported a lack of providers' knowledge of diagnostic and non-pharmacological treatment for DM 
[29]. Resolving the gaps in private providers' perception, knowledge, and skill is crucial to the TB-DM collaboration to be set-up appropriately [30].

The high risk of fragmentation as challenges regarding the continuity of TB-DM care related to the private sector was also portrayed. In line with a previous TB patient pathway research in Indonesia, PPCs in our study do not hold supporting examinations for TB by themselves due to the unavailability of laboratory and X-ray devices [14]. They also have no supplies of the standard drugs for TB treatment based on ISTC (International Standard for Tuberculosis Care) 2019. Additionally, insulin for DM treatment can only be prescribed by an internist in the referral hospitals or drug store collaborating with the BPJS-Kesehatan's Back-Referral Program. These incomplete and fragmented services at PPCs leads to low quality and delay in TB-DM care delivery.

While TB-DM collaboration has not yet been adequately developed in PPCs, our study showed that DM is beginning to manage in Indonesia thoroughly. Since BPJS-Kesehatan launched PROLANIS (chronic care program), PPCs have improved better organized for DM services. This condition differs from Nigeria that reported unpreparedness and inappropriate DM management as the major problems on TB-DM collaboration initiation. They noticed the lack of DM continuity of care system availability, inadequate knowledge and skills of providers about DM management, recurrent stockouts of DM supplies, the inability of the patient to pay for DM services, ineffective DM data management, and lack of government priority to DM care [30]. Comparing to TB management, a study in India reported the same issue, highlighted the lack of standardized DM treatment application as one crucial challenge in TB-DM collaboration [20]. DM management was commonly not adequately managed programmatically like TB, so one of the most important WHO TB-DM Collaboration for Care and Control initiative aims to enhance DM management by co-learning with TB [5,24].

It is interesting to note that the opportunity to involve private sectors in TB-DM collaborative control and service is widely opened. Flexibility in various healthcare funding sources, adjustable care pathway of non-BPJS patients, pre-existing routine health screening activities, a close relationship between private providers and patients, and BPJS membership transfer become opportunities to overcome the barriers. Apart from their limitations, PPCs as gatekeepers in Indonesia's health system could play some roles in implementing TB-DM collaboration regarding their main function in health prevention and promotion, conduct high-quality referral, and provide data reporting TB-DM program indicators.

Nevertheless, this research also had several strengths. This qualitative study explored providers' perspectives in-depth and provided rich data collected rigorously due to efforts to maintain trustworthiness. Although this study has clearly defined the current private sector situation in TB-DM collaboration, several limitations should be considered. The data interpretation is contextual; therefore, relevant quotations were used to describe their applicability in similar health system settings. Additional data from observations on care delivery in PPCs, document review, and other quantitative inquiries might be needed to assess service provision and program management of both diseases more comprehensively. 


\section{Conclusions}

This study provides insights into emerging health system barriers and opportunities that need to be addressed in integrating TB-DM services. Meanwhile, there are possible obstacles due to a lack of infrastructure, human resources, and healthcare coordination. The results indicate a wide opportunity to incorporate the TB control program into current DM treatment in PPCs. Besides their limitation, conduct health promotion, bi-directional screening, patient referring, and data reporting are PPCs' potential roles that could be continuously improved.

Therefore, it is essential to increase PPC involvement by enhancing their capacity and implementing PPM. PPC engagement should be initiated and maintained with multisector supports to ensure the sustainability of the program. Further work is required to piloting TB and DM integrated services in private healthcare facilities according to their potential roles. Assessment of feasibility for possible collaboration of services for the two comorbid diseases is needed to establish the two program integration.

\section{Abbreviations}

CHC Community Health Center

COREQ Consolidated criteria for reporting qualitative research

DHO District Health Office

DM Diabetes Mellitus

FERCAP Forum for Ethical Review Committees in the Asian and Western Pacific Region

FGD Focus Group Discussion

HCW Healthcare Worker

ICMJE International Committee of Medical Journal Editors

IDI In-depth Interview

GP General Practitioner

$\mathrm{NHI}$ National Health Insurance

PPC Private Primary Care

PPM Public-Private Mix

SIDCER Strategic Initiative for Developing Capacity in Ethical Review 
TACC Time-Age-Complication-Comorbidity

TB Tuberculosis

\section{Declarations}

\section{Availability of data and materials}

The datasets used and/or analyzed during the current study are available from the corresponding author on reasonable request.

\section{Ethics}

Ethical approval was obtained from the Medical and Health Research Ethics Committee (MHREC) Faculty of Medicine, Public Health, and Nursing at Universitas Gadjah Mada (Ref: KE/FK/0177/EC/2019). This study was in accordance with the CIOMS-WHO 2002 guidelines, as FERCAP-SIDCER recognized this Ethics Committee. For qualitative study reporting, we followed COREQ guidelines. Meanwhile, the authorship in this manuscript was under the ICMJE guidelines.

We collaborated with the Yogyakarta District Health Office to formally invite informants to the FGD activities as part of the TB-DM implementation research assessment. Written informed consent was obtained from informants, including for audio recording conversation. The application of alphanumeric code numbers was used to ensure the confidentiality of the participants. Code numbers in a list were used to identify the participants in the analysis. All the participants were given a modest financial reward for their time compensation.

Consent for Publication

$\mathrm{N} / \mathrm{A}$

\section{Availability of Data and Materials}

The datasets used and/or analyzed during the current study are available from the corresponding author on reasonable request.

\section{Competing interests}

The authors declare that they have no competing interests.

\section{Funding}

We would like to thank LP3M Universitas Muhammadiyah Yogyakarta, who has supported research funding.

\section{Author's Contributions}


MA is the principal investigator, prepared instruments, involved in data collection, conducted data analysis, led the development, and mainly drafted this manuscript. DS contributed to data collection and provided substantial input into the paper. IP contributed to testing the FGD guideline, data collection, interpretation of data and provided review of the manuscript draft. All three authors approved the final draft.

\section{Acknowledgment}

The highest appreciation goes to the District Health Office of Yogyakarta City, which has supported and facilitates this research. We are also thankful to Prof. dr. Adi Utarini, M.Sc., MPH., Ph.D. and dr. Riris Andono Ahmad, MPH, Ph.D. as supervisors of the present research.

\section{Author Information}

\section{Affiliations}

Department of Family Medicine and Public Health, Faculty of Medicine and Health Sciences, Universitas Muhammadiyah Yogyakarta, Jalan Brawijaya, Tamantirto, Kasihan, Bantul, Daerah Istimewa Yogyakarta, Indonesia

https://orcid.org/0000-0001-5193-6050

e-mail: merita.arini@umy.ac.id

Merita Arini

School of Nursing, Faculty of Medicine and Health Sciences, Universitas Muhammadiyah Yogyakarta, Jalan Brawijaya, Tamantirto, Kasihan, Bantul, Daerah Istimewa Yogyakarta, Indonesia

https://orcid.org/0000-0002-0793-9382

e-mail: dianita.sugiyo@umy.ac.id

Dianita Sugiyo

Master of Nursing, Post Graduate Program, Universitas Muhammadiyah Yogyakarta, Jalan Brawijaya, Tamantirto, Kasihan, Bantul, Daerah Istimewa Yogyakarta, Indonesia

http://orcid.org/0000-0002-8018-2275

e-mail: imanpermana@umy.ac.id

Iman Permana

\section{Corresponding author}


Correspondence to Merita Arini (merita.arini@umy.ac.id)

\section{Additional Information}

This study's results were presented orally at the $5^{\text {th }}$ International Conference of Hospital Administration at Yogyakarta, 2020 but not written on any proceedings or another publication.

\section{References}

1. International Union Against Tuberculosis and Lung Disease, World Diabetes Foundation. Bali Declaration on the Looming TB-Diabetes Co-Epidemic. IUALTD WDF. Published online 2015:1-3. http://www.theunion.org/bali-declaration.pdf

2. WHO. The top 10 causes of death. World Health Organization. Published 2018. Accessed September 3, 2020. https://www.who.int/en/news-room/fact-sheets/detail/the-top-10-causes-of-death

3. WHO. Global Tuberculosis Report 2020.; 2020. https://www.who.int/publications/i/item/9789240013131

4. Workneh MH, Bjune GA, Yimer SA. Prevalence and associated factors of tuberculosis and diabetes mellitus comorbidity: A systematic review. PLoS One. 2017;12(4):1-25. doi:10.1371/journal.pone.0175925

5. WHO. Collaborative framework for care and control of Tuberculosis and Diabetes. World Health. 2011;314(5805):2. doi:ISBN 9789241502252

6. Lönnroth K, Roglic G, Harries AD. Improving tuberculosis prevention and care through addressing the global diabetes epidemic: from evidence to policy and practice. Lancet Diabetes Endocrino. 2014;2(September):730-739. doi:10.1016/S2213-8587(14)70109-3

7. Alisjahbana B, van Crevel R, Sahiratmadja E, et al. Diabetes mellitus is strongly associated with tuberculosis in Indonesia. Int J Tuberc Lung Dis. 2006;10(6):696-700. http://www.ncbi.nlm.nih.gov/pubmed/16776459

8. Yorke E, Atiase Y, Akpalu J, Sarfo-kantanka O, Boima V, Dey ID. The Bidirectional Relationship between Tuberculosis and Diabetes. Tuberc Res Treat. 2017;2017(1702578).

9. Arini M, Ahmad RA, Utarini A. Tuberculosis and type 2 Diabetes Mellitus (TB-DM) comorbidity care: Barriers from the patients' perspective. Enferm Clin. 2020;30(S6):174-178. doi:10.1016/j.enfcli.2020.06.040

10. International Diabetes Federation. IDF Diabetes Atlas Ninth Edition 2019.; 2019. http://www.idf.org/about-diabetes/facts-figures

11. Mahendradhata Y, Trisnantoro L, Listyadewi S, et al. The Republic of Indonesia Health System Review. Heal Syst Transit. 2017;7(1):1-293. https://apps.who.int/iris/handle/10665/254716

12. Mahendradhata $Y$, Lestari T, Probandari A, et al. How do private general practitioners manage tuberculosis cases? A survey in eight cities in Indonesia Public Health. BMC Res Notes. 2015;8(1):17. doi:10.1186/s13104-015-1560-7 
13. Ahmad RA, Mahendradhata Y, Utarini A, de Vlas SJ. Diagnostic delay amongst tuberculosis patients in Jogjakarta Province, Indonesia is related to the quality of services in DOTS facilities. Trop Med Int Heal. 2011;16(4):412-423. doi:10.1111/j.1365-3156.2010.02713.x

14. Surya A, Setyaningsih B, Nasution HS, et al. Quality Tuberculosis Care in Indonesia: Using Patient Pathway Analysis to Optimize Public - Private Collaboration. JID. 2017;216(January):s724-s723. doi:10.1093/infdis/jix379

15. Mahendradhata Y, Utarini A, Lazuardi U, Boelaert M, Stuyft PVD. Private practitioners and tuberculosis case detection in Jogjakarta, Indonesia: Actual role and potential. Trop Med Int Heal. 2007;12(10):1218-1224. doi:10.1111/j.1365-3156.2007.01946.x

16. USAID. Engaging Private Providers to Improve TB Outcomes in Indonesia. U.S. Agency for International Development; 2018. https://pdf.usaid.gov/pdf_docs/PA00SWQD.pdf

17. WHO. Public-Private Mix for TB Care and Control: A Toolkit:; 2010.

18. Dinas Kesehatan Kota Yogyakarta. Profil Kesehatan Kota Yogyakarta Tahun 2019 (Data Tahun 2018):; 2019.

19. Carter N, Bryant-lukosius D, Dicenso A, Blythe J. The use of triangulation in qualitative research. Methods \& Meanings. 2014;41(5):545-547. doi:10.1188/14.0NF.545-547

20. India Tuberculosis-Diabetes Study Group. Screening of patients with tuberculosis for diabetes mellitus in India. Trop Med Int Heal. 2013;18(5):636-645. doi:10.1111/tmi.12084

21. Lei X, Liu Q, Escobar E, Philogene J, Zhu H, Wang Y. Public-private mix for tuberculosis care and control : a systematic review. Int J Infect Dis. 2015;34:20-32. doi:10.1016/j.ijid.2015.02.015

22. Mahendradhata Y, Lambert M-L, Van Deun A, Matthys F, Boelaert M, van der Stuyft P. Strong general health care systems: a prerequisite to reach global tuberculosis control targets. Int $J$ Health Plann Manage. 2003;18 Suppl 1(October 2001):S53-65. doi:10.1002/hpm.724

23. Gede IW, Eka A, Wayan N, et al. Factors associated to referral of tuberculosis suspects by private practitioners to community health centres in Bali Province, Indonesia. BMC Health Serv Res. 2013;13(1):1-6. doi:10.1186/1472-6963-13-445

24. Harries AD, Kumar AM V., Satyanarayana $S$, et al. Diabetes mellitus and tuberculosis: programmatic management issues. Int J Tuberc Lung Dis. 2015;19(8):879-886. doi:10.5588/ijtld.15.0069

25. Trisnantoro L, Herbianto D, Asrullah M, Sulistiawan D, Ekadinata N. Analisis Kebijakan Pembiayaan Program TB Dalam 3 Tahun Pelaksanaan Jaminan Kesehatan Nasional.; 2017.

26. Howard AA, El-Sadr WM. Integration of tuberculosis and HIV services in sub-Saharan Africa: Lessons learned. Clin Infect Dis. 2010;50(SUPPL. 3):S328-S244. doi:10.1086/651497

27. Basir MS, Habib SS, Zaidi SMA, et al. Operationalization of bi-directional screening for tuberculosis and diabetes in private sector healthcare clinics in Karachi, Pakistan. BMC Health Serv Res. 2019;19(1). doi:10.1186/s12913-019-3975-7

28. Workneh MH, Bjune GA, Yimer SA. Assessment of health system challenges and opportunities for possible integration of diabetes mellitus and tuberculosis services in South-Eastern Amhara Region, 
Ethiopia: A qualitative study. BMC Health Serv Res. 2016;16(1):1-11. doi:10.1186/s12913-016-1378-6

29. Ogbera OA, Adeyeye O, Odeniyi IA, Adeleye O. Knowledge of diabetes mellitus in tuberculosis amongst healthcare workers in Nigeria. Indian J Endocrinol Metab. 2013;17(4):704-708. doi:10.4103/2230-8210.113765

30. Li L, Lin Y, Mi F, et al. Screening of patients with tuberculosis for diabetes mellitus in China. Trop Med Int Heal. 2012;17(10):1294-1301. doi:10.1111/j.1365-3156.2012.03068.x

31. Zheng C, Hu M, Gao F. Diabetes and pulmonary tuberculosis: a global overview with special focus on the situation in Asian countries with high TB-DM burden. Glob Health Action. 2017;10(1):1264702. doi:10.1080/16549716.2016.1264702

32. Agrimon $\mathrm{OH}$. Exploring the Feasibility of Implementing Self-Management and Patient Empowerment through a Structured Diabetes Education Programme in Yogyakarta City Indonesia: A Pilot Cluster Randomised Controlled Trial. Univ Adelaide. 2014;(July). https://digital.library.adelaide.edu.au/dspace/bitstream/2440/87696/8/02whole.pdf

33. Ting X, Yong B, Yin L, Mi T. Patient Education and Counseling Patient perception and the barriers to practicing patient-centered communication: A survey and in-depth interview of Chinese patients and physicians. Patient Educ Couns. 2016;99(3):364-369. doi:10.1016/j.pec.2015.07.019

34. Poitras M, Maltais M, Bestard-denommé L, Stewart M, Fortin M. What are the effective elements in patient-centered and multimorbidity care? A scoping review. BMC Health Serv Res. 2018;18(446):1-9.

35. Barr VJ, Robinson S, Marin-Link B, et al. The expanded Chronic Care Model: an integration of concepts and strategies from population health promotion and the Chronic Care Model. Hosp Q. 2003;7(1):73-82. doi:10.12927/hcq.2003.16763

36. Boehmer KR, Dabrh AMA, Gionfriddo MR, Erwin P, Montori VM. Does the chronic care model meet the emerging needs of people living with multimorbidity? A systematic review and thematic synthesis. PLoS One. 2018;13(2):1-17. doi:10.1371/journal.pone.0190852

37. Naqvi SA, Naseer M, Kazi A, et al. Implementing a public-private mix model for tuberculosis treatment in urban Pakistan: Lessons and experiences. Int J Tuberc Lung Dis. 2012;16(6):817-821. doi:10.5588/ijtld.11.0440 